\title{
SKYWAY INNOVATION TECHNOLOGY FOR SMART CITIES
}

\author{
MARYIA DUNAYEVA \& MARYNA VINAKURAVA \\ SkyWay Technologies Co., Republic of Belarus
}

\begin{abstract}
Transport should be a solution to problems, not the source. This paper is intended to acquaint everyone who is interested in the development of the transport industry with the benefits of the SkyWay innovative transport system for smart cities. Another name for the SkyWay transport system is string transport, since it is based on an innovative string rail. The modern transport sector is the second largest atmospheric pollutant (after electricity and heat production). Emissions from the transport sector, contrary to the other sectors, are still growing and only recently their growth began to decline in developed countries. This study also includes comparison of the SkyWay technology with the other transport solutions. The aim is to justify that the use of the string transport on Earth is still the most balanced, proven and elaborated plan for development of cluster-type urban settlements. String transport is not a system, but a comprehensive complex that comprises dozens of systems and even more subsystems. The SkyWay elevated transport will be able to meet a whole range of communication requirements (not only transportation, but also energy and information requirements). At the same time, it is much more cost-efficient and effective compared to all available alternatives. In addition, this transport system is characterized by a high level of safety, durability and sustainability.
\end{abstract}

Keywords: elevated transport, electric vehicles, sustainability, linear city, overpass, string transport.

\section{INTRODUCTION}

It is no secret to anyone that modern transport has a number of disadvantages such as high accident rate and transportation problems, hazardous emissions and noise, low speed and high level of energy consumption, high level of construction and operational cost. Over 1.5 million people die on these roads and over a million are injured as a result of traffic accidents. "Rolled up" in asphalt and "buried" under railway sleepers is fertile soil, equal in its area to the territories of three countries, such as Israel. ITF Transportation Outlook research that provides an overview of recent trends and near-term prospects for the transport sector takes up a position that, globally, demand for mobility will continue to grow over the next three decades. Passenger transport will increase nearly three-fold between 2015 and 2050. Private vehicles will remain the preferred mode of personal travel worldwide [1].

Transport sector is the second largest atmospheric pollutant (after electricity and heat production). And in urban passenger transport, for example, the widespread adoption of shared and autonomous vehicles could cut $\mathrm{CO}_{2}$ emission by $73 \%$ and congestion by $24 \%$ in 2050 relative to current projections [2].

The latest 2018 annual assessment of the Global Carbon Project (GCP) demonstrates that the global greenhouse gas emissions will increase by $2.7 \%$ and are expected to rise to a new high of 37.15 billion tons in 2018 [3], with China and US as the two largest emitters, while China has made the most significant contribution to this growth in 2018. This is the largest increase in last seven years, and it is likely that $\mathrm{CO}_{2}$ emissions will increase further in 2019. The assessments of GCP members indicate that the increase in $\mathrm{CO}_{2}$ emissions from fossil fuels in 2018 leaves the world far from the trajectory needed to meet global climate goals.

Modern transport could solve one important socioeconomic problem - overcrowding of big cities. Everyone wants to live in small cozy towns or in a countryside and work in the capitals [4]. 


\section{STRING TRANSPORT AS THE METHOD FOR SOLVING TRANSPORT PROBLEMS}

\subsection{The basis of string transport technology}

The author of string transport technology is an engineer Anatoly Yunitsky - a scientist and inventor, the author of over 200 scientific papers, 18 monographs and more than 150 inventions in the spheres of construction, transport, machinebuilding, electronics and chemical industries. The idea of designing a string transport was born to the engineer while working on a project for a rocket-free space exploration. Then from the year 1977 and 1995 was written the monograph "String Transport Systems: on Earth and in Space". Now the developer of the string transport is SkyWay Technologies Company under brand SkyWay, created for these purposes in Minsk in 2014, whereas the patent holder and author is STS General Designer, Anatoly Yunitsky.

The main findings that made the author in the monograph is that any ground vehicle consumes energy not for efficient transportation but for overcoming environmental resistance and destruction on this environment. Therefore, improvements in transportation should be aimed not at increasing engine power, payload, passenger capacity or speed, as is the case now, but at reducing the resistance to movement - primarily in high-speed transportation (over $300 \mathrm{~km} / \mathrm{h}$ since many types of resistance increase in proportion to the velocity squared and cubed).

The main resistant to the movement of such a vehicle is aerodynamic resistance, which depends not only on the shape of the vehicle body and the quality of its surface but also on its placement relative to the track structure. The minimal possible value $\mathrm{Cx}$ for the vehicle placed close to the roadbed (as is the case with the car) is 0.2 due to the aerofoil effect created by fixed roadbed. A wingless vehicle flying at an altitude of $10 \mathrm{~m}$ or more has the lowest value $\mathrm{Cx}=0.1[4]$.

The difference in aerodynamic drag power is especially significant considering the scale factor. Suppose that 10 million high-speed modules will operate on 10 million km of roads in the future, considering that the length of the road network in the world exceeds 30 million $\mathrm{km}$ today. That makes one module per $1 \mathrm{~km}$ of tracks or one module per $600-800$ inhabitants, which is about 50 times less than cars. Then, the annual fuel consumption to overcome aerodynamic drag will amount to 12.2 billion tons for modules with a skirt and 6.8 billion tons for modules of a car type. This exceeds the anticipated oil production - according to the World Energy Council, the global oil consumption will reach 5.3 billion tons in 2020. The cost of annual fuel consumption by high-speed transport will be as follows: in the first case - 6.1 trillion USD, whereas in the second case - 3.4 trillion USD (based on the worldwide average fuel price of $0.5 \mathrm{USD} / \mathrm{kg}$ as of 2005). Only a wingless aircraft named "unibus" by the author features appropriate values. Such transport will consume 3.4 billion tons of fuel per year worth 1.7 trillion USD [4], [5].

Vehicles using an air cushion and magnetic suspension with a linear electric motor feature low performance as well. Not only do they have poor aerodynamics, but their suspension system is rather sensitive to the gap between the roadbed and the skirt. The gap in Transrapid, for example, should not exceed $10 \mathrm{~mm}$. A gap increase leads to a sharp drop in drive efficiency which does not exceed $40 \%$.

Taking into account the efficiency of power plants, the total energy efficiency of such a system makes about $10 \%$, while the modern steam locomotive efficiency reaches $15 \%$.

The wheel features better performance compared to other suspension systems of a highspeed vehicle relative to the track structure. However, a rubber (pneumatic) wheel is not 
suitable for high speeds since its rolling resistance at a speed of $100 \mathrm{~m} / \mathrm{s}$ increases and is nearly equal to 0.05 (i.e. its efficiency is 95\%). A steel wheel with an independent (automobile) suspension and a cylindrical support is characterized by the best performance. It is unlikely that a propulsion unit having efficiency higher than $99.9 \%$ will be invented for a high-speed vehicle in the 21 st century. Therefore, a steel rigid wheel will most probably continue to dominate in high-speed transportation as the most economically viable solution.

A considerable amount of resources will be required for creating the global network of high-speed roads in the 21 st century. In Russia alone, it is necessary to build at least 5 million $\mathrm{km}$ of new roads just to catch up with the USA in the 20th century. Meanwhile, three-quarters of the Russian territory is covered with marshes, permafrost, taiga and mountains, whereas its area by 1.8 times exceeds the area of the USA.

The most significant resource is alienated land. In the case of ground track laying, it will be required about 50 million hectares $\left(500,000 \mathrm{~km}^{2}\right)$ of alienated land. Considering an understated average value of this land of 200,000 USD/hectares, the cost of this resource will amount to 10 trillion USD. Therefore, the tracks should be laid above the ground on supports, at the second level.

There are two ways to create a superstructure between the supports: 1) using a rigid beam; or 2) using a highly stretched flexible thread. Since absolutely rigid systems do not exist, the design relative rigidity for spans of bridges and overpasses equal to $1 / 400-1 / 800$ was adopted worldwide as a compromise between the requirements for reduced material consumption for superstructures and the requirements for obtaining the highest possible value of the track structure rigidity under the impact of calculated moving load.

A calculation model with unique properties, the elements of which work in tension, is known from mechanics: loaded up to the materials tensile strength, it can carry even bigger additional load without collapsing. Despite low material consumption, the track structure will be not less rigid than massive conventional beam road and railway bridges. In fact, its deflection under the action of working load (transport modules) will be 1/1,000 and less of the span length.

The track can cover distance $l$ between the neighboring brake supports in one span $0.1-1 \mathrm{~km}$ and longer (without intermediate supports) at the sections with challenging terrain. In this case, the parabolic deflection of the sagging string track structure under the action of gravity force can be $0.001-0.01$ of $l$. In this way, it will be possible to overcome deep gorges, straits, distances between an island and a continent or between the tops of neighboring mountains, and other obstacles.

The track structure has no sags (Fig. 1(a)) at the main sections, i.e., at the sections with the length 10 (between backup supports 2), since the static deflection $y_{s}$ of string 3 is placed (hidden) inside its structure. The load of the track structure and transport module weight is transferred to the string via gasket 4 , the height of which varies along the span from zero (above the support) to the maximal value $\mathrm{y}_{\mathrm{s}}$ (in the middle of the span). Therefore, rail head 5 used for the movement of transport module wheels has an even surface under static conditions, without any joints or sags.

It is possible to design the system with the rail head working surface as a wavy line (Fig. 1(b)). Its form is a mirror reflection in relation to the direct line 8 of the track structure dynamic deflection $u_{d}$ at the time of transport module movement.

Oscillations will extinguish in a fraction of a second, therefore the time headway between the neighboring transport modules can be $20-50 \mathrm{~s}$.

In order to enhance string protection from any adverse external effects (mechanical, climatic, etc.) and increase track rigidity under a vehicle wheel, the string must be placed inside a special rail concreting them with each other using a high-strength composite [4]. 

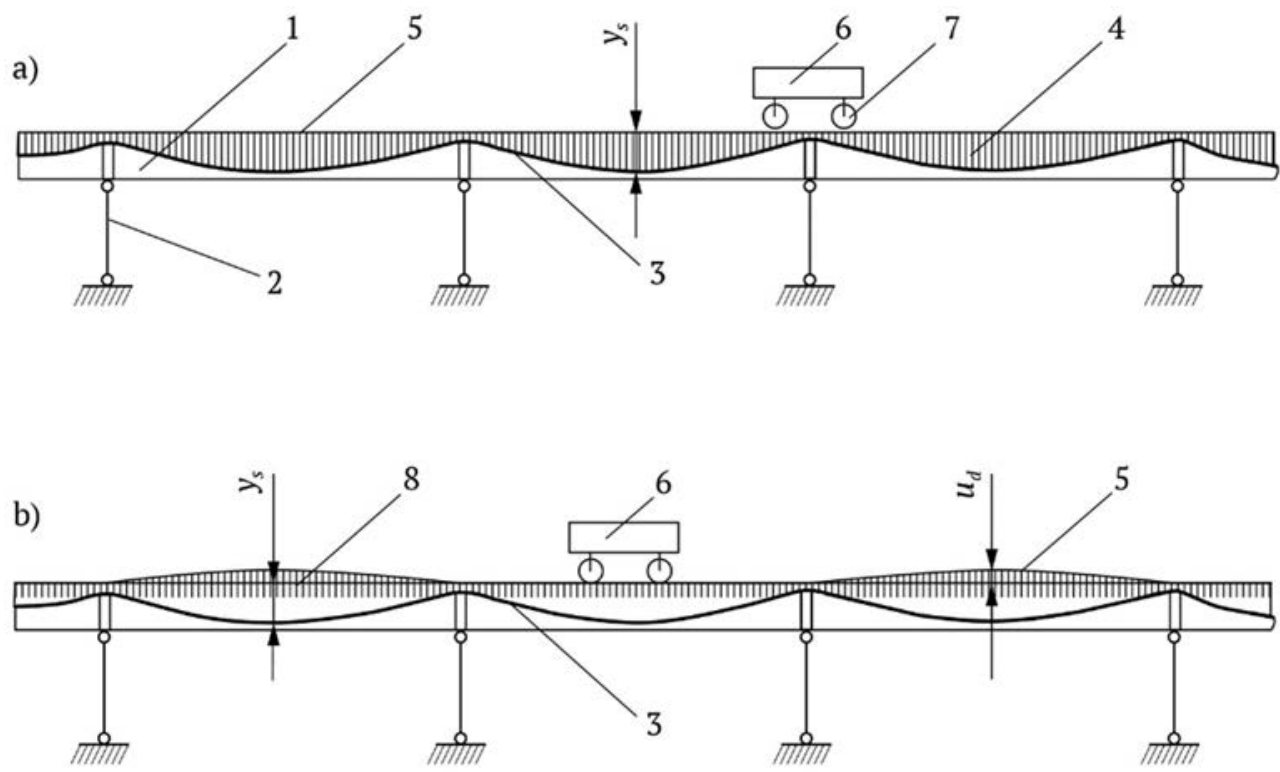

Figure 1: Diagram of longitudinal section for the string track structure. Track structure (a) without a sage; and (b) with a bulge (contracurvature).

So the basis of the track structure is uncut and ideally even string rails pre-stressed by tension, which together with the supports form a delicate but strong and durable transport overpass. A string rail is a steel, reinforced concrete or steel-reinforced concrete beam, continuous along the whole length. It is equipped with a rail head and additionally reinforced with strings pre-stressed by tension. Such a structure combines the qualities of a flexible thread at a big span between the supports, and a rigid beam at a small span and under the wheel of a rail car. The head of each rail is current carrying and electrically insulated from the bearing structure, supports and another rail. A flat rail head and a cylindrical steel wheel provide minimal energy consumption for movement. Fig. 2 shows a cross section for a semirigid string rail.

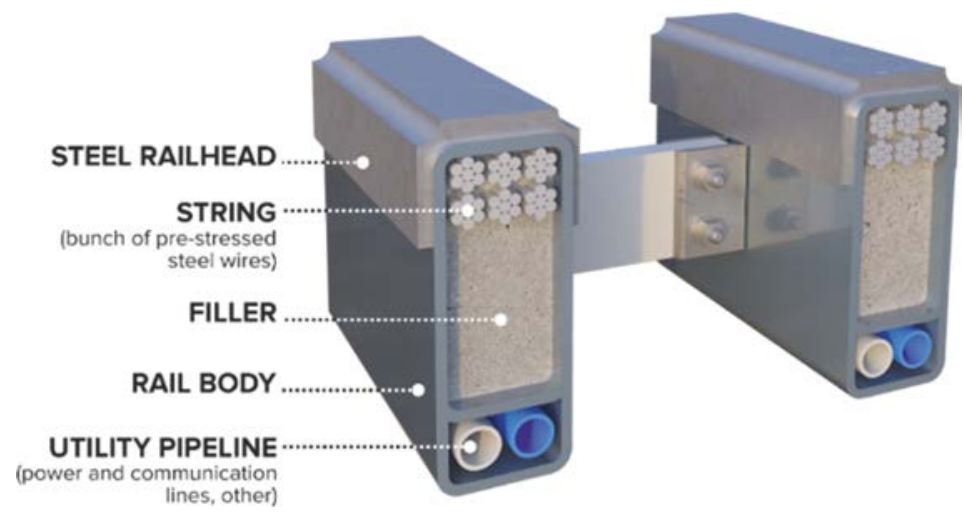

Figure 2: Semi-rigid rail cross section (design variant). 


\subsection{Design element of string transport}

\subsubsection{Track structure}

A traffic artery for the movement of transport modules is the basis of any transport system. As a rule, it is extremely material intensive (a roadbed, a rail track, bridges, tunnels, earthwork, etc.); therefore, its costs determine the main cost of the whole system. In this regard, the efficient use of physical and mechanical properties of materials in the structure of transport communications is very important [4].

The string transport moves on a track structure, which is based on two string rails designed in a special way. Strings are made of separate wires or stripes of high-strength material (for example, of steel) stretched with a tension of several hundred tons and mounted on light supports 5-50 $\mathrm{m}$ and higher, spaced from each other at the distance of 40-100 $\mathrm{m}$ and more. Transport modules are powered with electric energy via wheels in contact with string rails.

Depending on the given load, various types of track structures can be used. There are rigid (Fig. 3), semi-rigid (Fig. 4), flexible (Fig. 5) and coil tubing (Fig. 6) track structures in SkyWay technology which are selected depending on target passenger traffic or cargo traffic.

String wires, cables or strips can be made of any material, the tensile strength of which is over $5,000 \mathrm{kgf} / \mathrm{cm}^{2}$ : high-strength steel, aluminum or titanium alloys, glass fiber, carbonfilled plastic, fiber: boron, silicon carbide, aluminum oxide, carbon fiber, aramid and other high-strength polymer, ceramic or composite material.

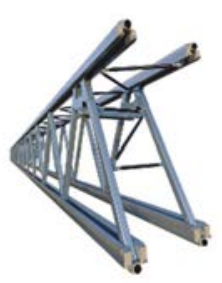

(a)

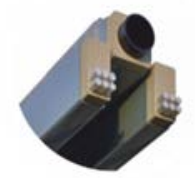

(b)

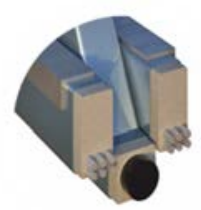

(c)

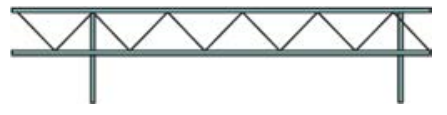

(d)

Figure 3: Rigid uncut track structure. (a) General layout; (b) Top chord (variant); (c) Bottom chord (variant); and (d) Rigid track structure layout.

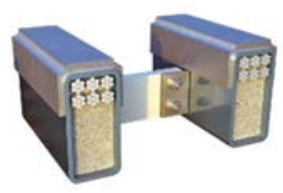

(a)

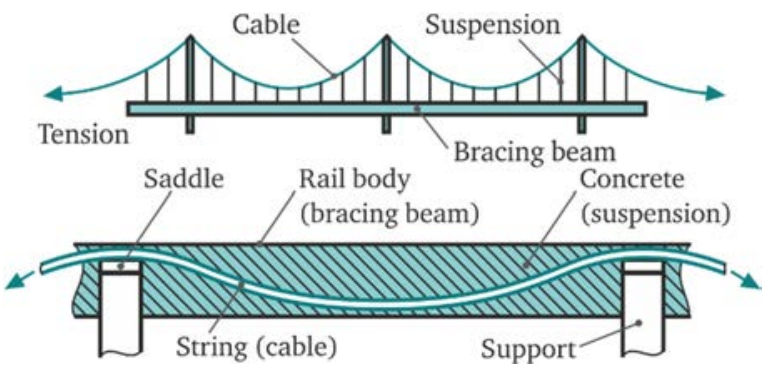

(b)

Figure 4: Semi-rigid uncut track structure. (a) General layout; and (b) The track structure follows the design of a hanging bridge. 


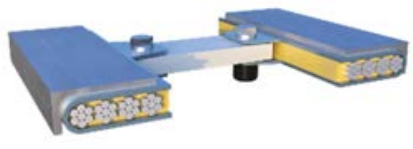

(a)

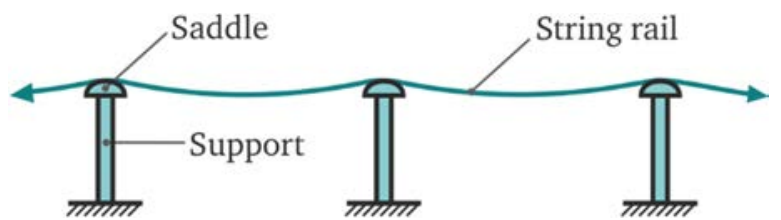

(b)

Figure 5: Flexible uncut track structure. (a) General layout; and (b) Flexible track structure layout.
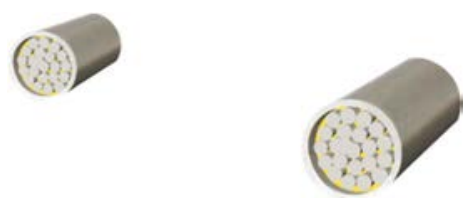

Figure 6: Coil tubing track structure.

A rail head can be made of metal, ceramics (metal ceramics), polymer (metal polymer), composite and other high-strength, wear resistant and conductive material - homogeneous or multilayer material, for example, with a special wear resistant renewable coating. The following can be used as filler material: monolithic or poromeric (expanded) polymeric materials, metal, ceramic and composite material, various concretes or polymer concretes, as well as various fiber material - with closed or communicating pores, filled with special liquid, consistent or solid fillers [4].

\subsubsection{Supports}

The string transport supports are divided into three characteristic types (Fig. 7), which differ in the amount of horizontal (longitudinal) load, acting in the process of track construction and operation: (a) intermediate (backup) support (2); (b) brake support (4); (c) anchor support (3).

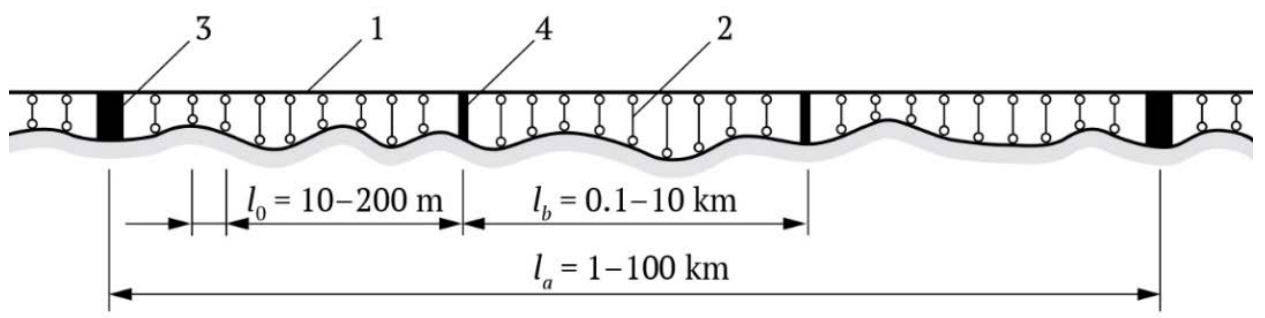

Figure 7: Linear scheme of string road route.

Anchor supports can be structural foundations for intermediate passenger transfer stations and cargo terminals. With the general functional purpose, anchor supports are carried out of two types depending on the availability of stopping points on them. The anchor station exterior can be made compatible with the architecture and the landscape of their location. The height of anchor supports depends on landscape and infrastructure development. 
Intermediate supports are spaced in intervals of 25-100 $\mathrm{m}$ (for providing required high rigidness of uncut track structure). Supports can be U-shaped, T-shaped and L-shaped and from several to dozens meters high. The installation of an intermediate support head to the track structure allows to increase its capacity by eight times [4].

\subsubsection{Terminals, stations and depot}

Intermediate stations and terminals with intensive passenger flows could be equipped with turnout switches and sheds to enable the circulation of vehicles independently of the traffic schedule. The stations with small passenger flows may be designed as open platforms located on the route. Passenger boarding (alighting) is carried out on them when braking single not fully-loaded vehicles. Depots are usually located at the terminal stations but it depends on the length of the route.

\subsubsection{Rolling stock}

The rolling stock movement on the SkyWay track structure is carried out by means of wheels used to collect current and supply electric power to the drive (as a variant).

According to the SkyWay transport system technology, the principle of modular construction both for nodal solutions and the structure of a rail car itself is applied for the vehicle - a rail car on steel wheels. In addition, an operatorless control on the route based on the program control on the principles of "autopilot".

Rolling stock could be in both monorail and double-rail design variants. In Fig. 8 there are pictures of urban rolling stock called Unibike, Unibus and Unicar. The capacity of transport is from 2 to 175 passenger in coupled pods.

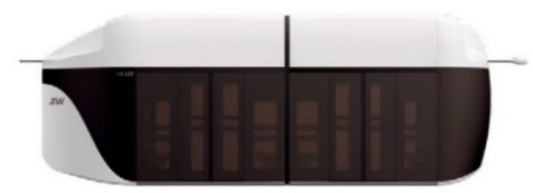

(a)

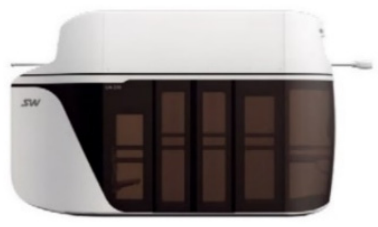

(b)

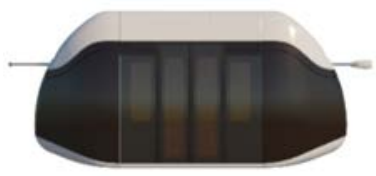

(c)

Figure 8: Urban SkyWay transport modules. (a) Large class double-rail unibus (passenger capacity: 7-60 people; in articulated vehicles - up to 84-600); (b) Middle class monorail unibus (passenger capacity: 3-14 people; in articulated vehicles - up to 84 ); and (c) Small class monorail unicar (passenger capacity: 2-6 people; in articulated vehicles - up to 6-60). 
Maximum design speed of SkyWay vehicles in the city is $150 \mathrm{~km} / \mathrm{h}$. Track declivity is up to $15 \%$, with special design up to $30 \%$.

As the time headway between the neighboring transport modules can be $20-50 \mathrm{~s}$, this will provide the ultimate capacity of the string transport. For the urban and suburban transport complex maximum rush hour, capacity is up to 50,000 passengers per hour (365 million passengers/year) [4].

Advantages of SkyWay transport models are:

- Insignificant contact stress (less than $200 \mathrm{MPa}$ ) due to a wide contact patch (by rail head width);

- $\quad$ No slipping in the contact patch (cylinder rolling along the plane);

- $\quad$ Disk brake mechanisms and ABS preventing wheels locking;

- Small wheel load and absence of joints on the track;

- Symmetrical rail head wear (vertically and horizontally);

- Minor wheel rolling resistance due to a narrow contact patch (in the direction of wheel rolling).

State examination and international certification of four types of the vehicles has been passed (We obtained certificates confirming technical features of SkyWay transport rolling stock and its components). The Certificates were issued by LLC "Scientific-technical center of Scientific Research Institute Gorelectrotransport" having a corresponding accreditation at the Ministry of Transport of the Russian Federation.

An international certificate confirming compliance of the quality management system applied in SkyWay Technologies Co. to the international standard ISO 9001:2015 is entered into the register of the certifying agency "TÜV Thüringen".

\subsubsection{Intelligent control system}

The automated safety, control, power supply and communications system in the SkyWay technologies is distributed. It consists of the following components (Fig. 9):

1. Intelligent control system:

- rolling stock (configuration and cost depend on pods number);

- traffic control room, stations equipment control system (configuration and cost depend on stations number and its type, passenger traffic);

- linear control system (configuration and cost depend on route length).

2. Power supply system (contact system).

3. User interaction platform.

\subsection{SkyWay as compared to other transport}

SkyWay transport system are often compared to cable cars, monorails or LRT. Let us investigate the differences between these types of transport [6].

\subsubsection{SkyWay comparison to cableway}

Due to the location above the ground, SkyWay tracks are often compared to the cableway (Table 1). The principle of the cableway is the movement of the cable, on which the cars are fixed, between two points. In SkyWay, the vehicle (electric rail vehicle) is not moving along a cable that requires regular replacement every $6-8$ years, but on a steel profile. When moving at the same speed, energy consumption in the string railroad will be 5-6 times lower 


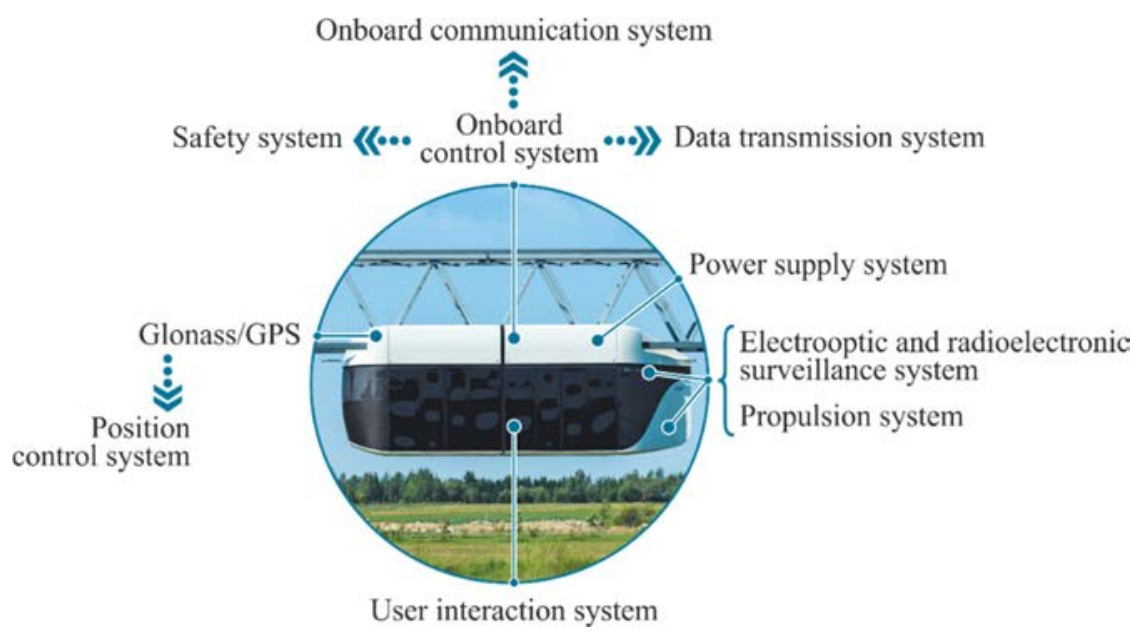

Figure 9: The control system of SkyWay transport complex.

Table 1: SkyWay and cableway comparison.

\begin{tabular}{|l|l|l|}
\hline Characteristics & Cableway & SkyWay \\
\hline Speed & $21.6 \mathrm{~km} / \mathrm{h}(6 \mathrm{~m} / \mathrm{s})$ & Up to $150 \mathrm{~km} / \mathrm{h}$ (in city) \\
\hline Track length & Up to $10 \mathrm{~km}$ & Unlimited \\
\hline Principle of movement & $\begin{array}{l}\text { Outboard motor moves } \\
\text { both cable and cars }\end{array}$ & Autonomous steel-wheeled \\
\hline Turning capability & No & Yes \\
\hline Service life & $\begin{array}{l}\text { Complete replacement of } \\
\text { cables each 6-8 years }\end{array}$ & $\begin{array}{l}\text { Track structure: } 50-100 \text { years; } \\
\text { Rolling stock: } 25 \text { years }\end{array}$ \\
\hline Safety & Low & High \\
\hline Comfort & No climate control & Climate control \\
\hline Cost effectiveness & Low & High \\
\hline
\end{tabular}

compared to the cableway. SkyWay surpasses the cableway in a range of parameters operating costs, service life, safety, speed, performance. It is worth noting that SkyWay, in contrast to the cableway, has various types of tracks, making it possible to combine them, and a wide range of vehicles.

\subsubsection{SkyWay comparison to LRT}

We could compare SkyWay mounted transport with LRT in the city (Table 2). SkyWay mounted vehicles we can use only in terms of high passenger flows. But here we can see that SkyWay vehicles capacity is much more attractive than the LRT.

\subsubsection{SkyWay comparison to monorail}

Compared to monorail SkyWay wins primarily in speed (Table 3). In addition, monorail as usual has very massive overpass, with high material capacity; and economically nowhere justified. 
Table 2: SkyWay and LRT comparison.

\begin{tabular}{|l|l|l|}
\hline Characteristics & LRT & SkyWay \\
\hline $\begin{array}{l}\text { Rolling stock } \\
\text { capacity }\end{array}$ & $\begin{array}{l}\text { Train: from 4-5 cars from up to } \\
100 \text { passengers each. } \\
\text { Platform length: minimum } 150 \mathrm{~m}\end{array}$ & $\begin{array}{l}\text { Coupled unibuses: up to 240 } \\
\text { people on the upper track and up } \\
\text { to 175 people on the lower track. } \\
\text { Platform length: up to 50 m }\end{array}$ \\
\hline Headway & From 1-2 minutes & From 20-25 seconds \\
\hline Safety & Medium & High \\
\hline
\end{tabular}

Table 3: SkyWay and monorail comparison.

\begin{tabular}{|c|c|c|}
\hline Characteristics & Monorail & SkyWay \\
\hline Track length & $\mathrm{Up}$ to $50 \mathrm{~km}$ & Unlimited \\
\hline Rolling stock capacity & $\begin{array}{l}\text { Train: from } 4 \text { cars for up } \\
\text { to } 80 \text { passengers and more } \\
\text { each. } \\
\text { Platform length: minimum } \\
100 \mathrm{~m}\end{array}$ & $\begin{array}{l}\text { Coupled unibuses: up to } 240 \\
\text { people on the upper track and up } \\
\text { to } 175 \text { people on the lower track. } \\
\text { Platform length: up to } 50 \mathrm{~m}\end{array}$ \\
\hline Maximum speed & $70 \mathrm{~km} / \mathrm{h}$ & $150 \mathrm{~km} / \mathrm{h}$ \\
\hline Principle of movement & $\begin{array}{l}\text { Elevated pneumatic-tired } \\
\text { transport }\end{array}$ & $\begin{array}{l}\text { Autonomous steel-wheeled } \\
\text { vehicles }\end{array}$ \\
\hline Headway & 5-20 minutes & From $20-25$ seconds \\
\hline Service life & $\begin{array}{l}\text { Track structure: } 50 \text { years; } \\
\text { Rolling stock: } 10-15 \\
\text { years }\end{array}$ & $\begin{array}{l}\text { Track structure: } 50-100 \text { years; } \\
\text { SkyWay rolling stock: } 25 \text { years }\end{array}$ \\
\hline
\end{tabular}

\section{SKYWAY TRANSPORT SYSTEM FOR SMART CITIES}

\subsection{SkyWay linear city concept}

For smart cities SkyWay offers particular system the basis for which is a network of smart linear cities built along transport communications of an elevated type [7], [8].

Linear City is a cluster-type urban settlement, where the surface of the earth is meant for pedestrians and green plants, while transport, energy and information networks are elevated above the ground on the "second level". There is only one mode of transportation in the city - horizontal lifts connecting the high-rise towers, spaced at $500 \mathrm{~m}$ and more (up to $3 \mathrm{~km}$ ) from each other and placed along one line, or several parallel and intersecting lines. In the center, there is a dominator - a high-rise building with public establishments, through which transport, power supply and information communication lines pass, located at a height of 10 meters and more above the ground surface, i.e. on the "second level". Interchange stations to transfer from urban tracks (their speed - up to $150 \mathrm{~km} / \mathrm{h}$ ) to high-speed intercity air tracks (their speed - up to $500 \mathrm{~km} / \mathrm{h}$ ) and, potentially in the future, underground hyperspeed tracks located in four vacuum tubes (their speed - up to $1,500 \mathrm{~km} / \mathrm{h}$ ) are also placed in them (Fig. 10) [7], [8]. 


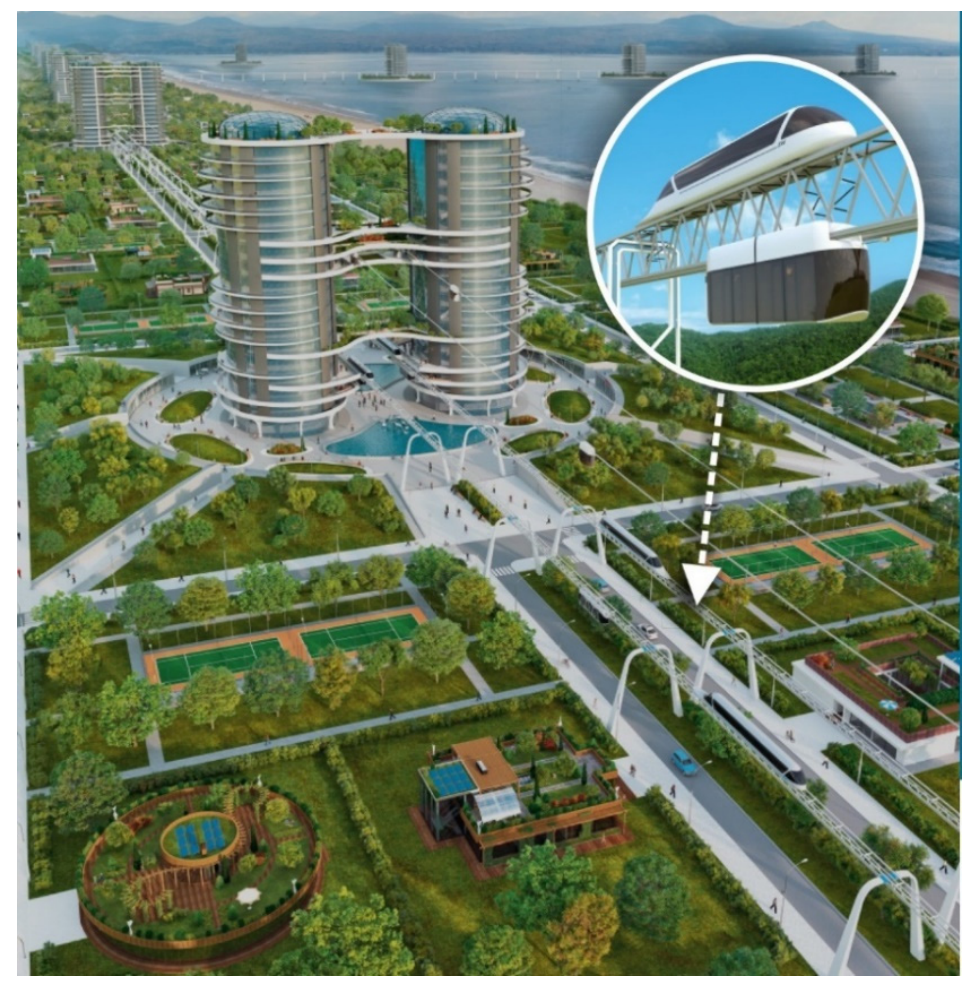

Figure 10: SkyWay linear city.

The horizontal lifts are the key element of the system - they are the transport arteries connecting neighboring high-rise buildings, settlements, residential, shopping, entertainment and other clusters, allowing for comfortable transit within a few minutes. An important advantage is that the cost of the public transport can be included, as it is done with conventional elevators in the buildings, into the square meter price of the linear city premises, while keeping the average market price for new residential premises.

Every cluster is self-contained - it is provided with its own energy, water and food. It does not deprive nature of a single square meter of land - soil from under every building is transferred to a flat roof of the building, enriched with fertile humus, with a garden planted on it.

There will be no traffic jams, smog or traffic-related deaths in such a pedestrian linear city. It will become possible for children to run barefoot not on asphalt, but on grass, and parents will not have to worry about their life. All population will be employed, mainly in services sector, including growing of natural food for their families.

The resource intensity during construction, operation and repairs - metal, concrete, asphalt, earthwork operations and land acquisition - will be ten times less if compared to the implementation of any other transport and infrastructure solutions. In its essence, the future vision of a Smart State proposed by the SkyWay is not a transport project, but an infrastructure and development one. Therefore, it can be entirely implemented at the cost of population of the country by creating domestic demand in all areas of economy - from agriculture and construction to machine building and electronics [7], [8]. 


\subsection{Blockchain technology for SkyWay string transport}

Blockchain is a unified global, extensible and flexible system through smart contracts, which has made it possible to establish a new platform of programmable values and obligations of different purposes and scale.

The SkyWay project did not stay aside from the trend towards automation: initially, the function to manage the traffic on the basis of sensor readings collected and processed by using the artificial intelligence was developed in SkyWay transport systems.

In SkyWay transport modules, collection of such data is performed with the help of sensors and detectors of several types. Information from these sensors is collected and transferred continuously to the control center, where routing tasks are formed and adjusted. In addition, the transport module can make decisions on its own; only the most general instructions come from the central control room - to determine the place and time, when the measures should be taken.

To control the traffic, the rolling stock is equipped with a set of cameras and radars, which allow to identify more than 90 different types of objects, as well as estimate the parameters of their movement - speed and range to an object. The "radar + camera" combination was specially chosen by the SkyWay Engineers: this set allows to identify obstacles under severe weather conditions and at the same time does not require such high expenses as a lidar (light detection and range measurement).

The economic model is based on token 3.0, which is built into each rail, each sensor, each turnstile and user's mobile device. The token, as a token or coupon, is used to pay for travel and also helps to distribute the profits proportionally among all stakeholders, including investors, who have invested in the complex or in a specific section of the track structure or other infrastructure object. Distribution is performed automatically without involvement of any intermediaries.

The blockchain technology allows you to implement the automated mutual settlement between suppliers and consumers of the fuel and power supply network. The networkpowered vehicles are equipped with onboard individual electricity metering devices and connected permanently to the network. The devices operate in two-side mode on the basis of the Smart Grid principle: i.e. when moving, the power source consumes electricity from the network, and when braking - works as a generator by returning the energy to the network. Each device at the moment of use is tied to the consumer's smart contract. To maintain "the feeding" of the transport device with power from the network, the consumer should maintain a certain balance of tokens.

\section{CONCLUSION}

The author of the technology nowadays assembled in the Republic of Belarus and UAE teams that implement string transport since 2014. As a result, our technocratic civilization will be able to solve global environmental problems and challenges and live on the Earth comfortably and safely in harmony with Nature. Anatoly Yunitskiy - the founder of string transport - concludes that $90 \%$ of the energy expenditure during its movement goes to aerodynamic resistance. Here SkyWay achieved great success: the drag coefficient of rail car, called "unibus", is seven times lower than that of the Bugatti. Elevated transport improves aerodynamic by 2.5 times. The track structure is uncut and pre-stressed by stretching special: strings, thanks to which our tracks; have no expansion joints; have low material consumption and high durability; provide high evenness; are much cheaper than other elevated transport systems. 
SkyWay vehicles are driven by artificial intelligence; motor wheels (high-performance electric motors fitted into steel wheels) move them. Confidential information flows within the transport complex are protected using Blockchain technology. From virtually every known area of technology, we take the best, process and embed it into the string transport to make it even more efficient. However, the main thing that allows us to come closer to perfection is the maximum attention to the laws of physics: the science of Nature, broadly speaking.

\section{REFERENCES}

[1] Hooftman, N., Oliveira, L., Messagie, M., Coosemans, T. \& van Mierlo, J., Environmental analysis of petrol, diesel and electric passenger cars in a Belgian urban setting. Energies, 9(2), p. 84, 2016.

[2] CarbonBrief. Analysis: Fossil-fuel emissions in 2018 increasing at fastest rate for seven years. www.carbonbrief.org/analysis-fossil-fuel-emissions-in-2018-increasing-atfastest-rate-for-seven-years. Accessed on: 28 May 2019.

[3] European Commission, Energy Roadmap 2050: A Practical Guide to a Prosperous, Low Carbon Europe: Technical and Economic Assessment, Vol. I., Publications Office of the European Union: Luxembourg, 2012.

[4] Unitsky, A.E., String transport systems: On Earth and in space. http://yunitskiy.com/author/2019/2019_26en.pdf. Accessed on: 28 May 2019.

[5] Unitsky, A.E., High-Speed road transport NTL. The International Scientific and Practical Conference. Resource and Energy Saving Technologies in a Transport and Construction Complex, Gomel, pp. 69-70, 1995.

[6] Unitsky, A.E., SkyWay vs. Other Types of Transport, SkyWay: Minsk, p. 18, 2018.

[7] Unitsky, A.E., Smart country of India. International Exhibition Smart Cities India, New Delhi, 2017.

[8] Unitsky, A.E., SkyWay string transport: From smart-transport to smart-state. Transport Strategy - XXI Century, 38, pp. 16-19, 2017/2018. 